\title{
Quorum sensing inhibition in Vibrio fischeri: An efficient system to assess antibacterial properties of medicinal plants and their volatile compounds
}

\author{
Devanshi M Shukla ${ }^{1,2}$, Vikramjit Bajwa ${ }^{2}$, Dragan Gajic ${ }^{3}$ and Praveen K Saxena ${ }^{2 *}$ \\ ${ }^{1}$ Gosling Research Institute for Plant Preservation, Department of Plant Agriculture, University of Guelph, Guelph, ON, Canada, N1G 2W1 \\ ${ }^{2}$ Department of Biology, University of Western Ontario, London, ON, Canada, N6A 3K7 \\ ${ }^{3}$ Centennial Collegiate Vocational Institute, Guelph, ON, Canada, N1G 1S9
}

\begin{abstract}
Many medicinal plants are commonly used for their antimicrobial properties, and their effects have been studied in depth. However, there is a need for an efficient bioassay to determine the effectiveness of the antimicrobial compounds in comparison with each other. In this study, the inhibition of quorum sensing in $V i b r i o$ fischeri tested as a reduction of bioluminescence was used to assess the antibacterial properties of six medicinal plants. Furthermore, seven different essential oils and six different volatile compounds were evaluated for their volatile effect on the inhibition of bacterial growth and communication. Holy basil extract was the most efficient in reducing the luminescence and cell population of $V$. fischeri. The known compounds of holy basil essential oil; linalool and eugenol, were identified as powerful antibacterial agents, not only through their direct contact but through their volatile effects as well. The antibacterial effects of linalool and eugenol were confirmed by testing their effects on pathogenic bacteria, Chromobacterium violaceum and E. coli. All compounds showed varying degrees of bacterial growth inhibition in a dose dependent pattern. This bioluminescent bioassay is a novel approach for an efficient screening of the antimicrobial properties of medicinal plants. The bioassay can be extended to screen new medicinal plant compounds, evaluating either their direct contact or volatile effects on bacteria for testing the antimicrobial efficiency of a range of natural health products.
\end{abstract}

\begin{abstract}
Abbreviations: WHO - World health organization; CFU - Colony forming unit; LB - Luria-bertani medium; OD - Optical density; ANOVA - Analysis of variance; ATCC - American type culture collection.

\section{Introduction}

Antibiotic resistant bacteria are becoming increasingly common due to the excessive use and under dosing of antibiotics. More than 23,000 deaths were reported in 2014 due to antibiotic resistant infections in the USA alone [1]. Alternatives to conventional antibiotics are necessary to reduce the increase of antibiotic resistance in common bacterial strains [2]. Medicinal plant extracts have the possibility to serve as effective alternatives to current synthetic antibiotics as they contain a multitude of metabolites, and it is unlikely for bacteria to gain resistance to such a range of compounds [3-5]. The World Health Organization (WHO) recommends the use of natural health products for the treatment of several common infections as a measure to reduce the risk of increased antibiotic resistance in bacteria [6,7]. Medicinal plants and their metabolites such as flavonoids, phenolics, alkaloids and essential oils are well documented for their antimicrobial properties [813] and are commonly used in home remedies throughout the world [2]. The current methods for screening the antimicrobial properties of plants and their compounds are labour intensive, expensive and species dependent. These methods are also not well suited for testing the antibacterial effects of plant volatiles $[14,15]$. Thus, an efficient bioassay for determining the effectiveness of antibacterial properties of plants and their compounds is needed to screen antimicrobial medicinal plants.
\end{abstract}

The quorum sensing inhibition offers an effective way to test for the efficiency of the antibacterial properties in plants. Quorum sensing is a population dependent mechanism in bacteria that allows for the expression of group behaviour genes. Group behaviours such as virulence, antibiotic resistance and bioluminescence are controlled by genes that are only expressed when there is quorum sensing. Therefore, disrupting this signalling mechanism can effectively control bacterial infections, since reduced bacterial communication results in the inhibition of the expression of genes responsible for virulence and antibiotic resistance. Antimicrobial efficiency of medicinal plant extracts can be quantified by observing quorum sensing inhibition. A bioluminescence based method of determining the inhibitory effects of medicinal plants on quorum sensing can be highly effective in improving research practices and ultimately, public health. A very promising alternative to observing quorum sensing inhibition in bacteria is through the observance of bioluminescence in $V$. fischeri $[16,17]$. Quorum sensing in V. fischeri can be visually observed as bioluminescence and is a result of the expression of group behaviours genes, turned on only at specific population densities [16].

${ }^{\star}$ Correspondence to: Praveen Saxena, $\mathrm{PhD}$, Professor and Director, 50 Stone Road East, Department of Plant Agriculture, University of Guelph, Guelph, ON, Canada, N1G 2W1, Tel: (519)824-4120 ext. 52495; Fax: (519)767-0755; E-mail: psaxena@uoguelph.ca

Key words: bioluminescence, bacterial disease, antimicrobial properties, essential oil, health product

Received: April 11, 2020; Accepted: May 05, 2020; Published: May 08, 2020 
V. fischeri is a Gram-negative, rod-shaped bacterium that bioluminesces through this population-dependent mechanism. $V$. fischeri collectively luminesce when the certain colony number is reached. This luminescence reaction is catalyzed by the enzyme luciferase. As expressed below, the long-chain aliphatic aldehyde is oxidized and a flavin mononucleotide (FMNH2) is reduced which generates luciferin (FMN), the oxidized form of the aldehyde, water, and excess free energy in the form of a blue-green light at $490 \mathrm{~nm}$ [18]: $\mathrm{nm})$

$\mathrm{FMNH} 2+\mathrm{RCHO}+\mathrm{O} 2---->\mathrm{FMN}+\mathrm{RCOOH}+\mathrm{H} 2 \mathrm{O}+$ light $(490$

Bioluminescence intensity reflects the overall health of the bacteria and gives an idea of the amount of autoinducer production, which are hormone molecules that allow for this group gene expression [19-21]. The population dependent bioluminescence of $V$. fischeri is sensitive to antibacterial agents due to lowered bacterial cell growth and therefore has a potential to be used as a technique for screening antibacterial plants [19,22-24]. However, no such bioassay to test the antibacterial properties of plants and their volatiles has been developed.

In the present study, we used the population dependent inhibition of $V$. fischeri bioluminescence as a technique to test and quantify the antibacterial efficacy of medicinal plants and their compounds. The findings of this study indicate that this bioassay is a rapid, simple, and precise method to test a wide spectrum of antibacterial medicinal plants through the suppression of $V$. fischeri quorum sensing.

\section{Materials and methods}

\section{Bacterial strains}

Vibrio fischeri and Escherichia coli strain DH5a were obtained from Invitrogen, Canada and the cultures of Chromobacterium violaceum (ATCC-31523) were provided by Dr. Joseph Lam, University of Guelph. All bacterial strains were maintained on Luria-bertani (LB) medium in Petri dishes $(100 \mathrm{~mm} \times 15 \mathrm{~mm}$; Fisher Scientific, Canada) and the liquid culture medium was dispensed in $125 \mathrm{ml}$ Erlenmeyer flasks. However, the LB medium was supplemented with additional $10 \mathrm{~g} / \mathrm{L}$ $\mathrm{NaCl}$ for $V$. fischeri [24]. Agar (1.5\%) was added to the LB medium for solidification.

\section{Inoculum preparation}

V. fischeri was cultured by adding a bacterial colony into a sterile flask containing $15 \mathrm{~mL}$ of liquid LB medium; the flask was then placed on a shaker at room temperature for $22 \mathrm{~h}$. The resulting concentrated $V$. fischeri solution was serially diluted six times with LB medium in a $2 \mathrm{~mL}$ sterile Eppendorf tube. A consistent volume of $100 \mu \mathrm{L}$ from each dilution was plated onto LB medium in three Petri dishes and incubated at room temperature for $24 \mathrm{~h}$ for growth in order to achieve the targeted initial concentration of 30 - 200 colony forming units (CFU). Based on visual count, 179 CFUs were obtained at $0.01 \%$ concentration of the bacterial culture and used for all subsequent experiments.

Flasks containing bacterial cultures were kept on shakers at 150 $\mathrm{rpm}$ for $24 \mathrm{~h}$ at $22-25^{\circ} \mathrm{C}$ in a dark room, until they reached peak luminescence as described by Boynton [24]. Semi-solid plates were kept in a growth cabinet under the same incubation conditions.

\section{Plant material, volatile oils and volatile compounds}

Dry seed powder of cumin, nutmeg, coriander and dry rhizome powder of turmeric were locally procured from Nofrills ${ }^{\mathrm{si}}$, Ontario, Canada. Fresh leaves of holy basil and Artemisia were collected from plants grown in greenhouses at the Plant Agriculture Department, University of Guelph, Canada. The clone lines of both holy basil and Artemisia were maintained under in vitro conditions and later transferred to the greenhouse for 8 weeks before harvesting the leaves. Leaves of holy basil and artemisia were dried in indirect sunlight for $72 \mathrm{~h}$ and were then stored at $4^{\circ} \mathrm{C}$.

Volatile oils of cinnamon (Cinnamomum verum), anise (Pimpinella anisum), cassia (Cassia fistula), clove (Eugenia caryophyllata), spearmint (Mentha spicata), lemon (Citrus limon) and lavender (Lavandula angustifolia) were procured from LorAnn ${ }^{\text {twe }}$ oils, Lansing, MI, USA.

Volatile compounds such as linalool, methyl salicylate, citral, eugenol, menthol and cumin aldehyde were procured from SigmaAldrich, Canada.

\section{Preparation of plant material extracts}

Dry powder ( 0.5 grams) of each of the plant materials was added to $100 \mathrm{~mL}$ of water, boiled at $75^{\circ} \mathrm{C}$ for $30 \mathrm{~min}$ and filter sterilized using a $0.22 \mu \mathrm{m}$ filter (Fisher Scientific, Ontario). Five dilutions $(0,0.1,1,5$ and $10 \%(\mathrm{v} / \mathrm{v}))$ of the extracts were used in the assays to evaluate the inhibitory effect of the extract on growth of $V$. fischeri.

\section{Assessment of efficacy of plant extracts}

Kirby Bauer disc diffusion assay: This assay was used to evaluate the size of zone of inhibition by plant extracts. A $0.01 \%$ concentration of $V$. fischeri culture was spread evenly using a loop on LB plates. Two paper discs (10 $\mathrm{mm}$ in diameter) were dipped in the plant extracts mentioned above at varying concentrations $(0,0.1,1,5$ and $10 \%)$, and placed onto the LB medium in Petri dishes. All cultures were kept in the growth conditions described earlier and observations for zones of inhibition were recorded after $24 \mathrm{~h}$.

Liquid culture assays: $500 \mu \mathrm{L}$ of each dilution $(0,0.1,1,5$, and $10 \%)$ of each plant extract were added to separate $50 \mathrm{~mL}$ Erlenmeyer flasks, containing $7 \mathrm{~mL}$ of liquid LB medium. Flasks were inoculated with $10 \mu \mathrm{L}$ of $V$. fischeri bacterial culture that was initially grown by scraping a colony off a Petri plate with a $V$. fischeri culture. The flasks were placed on a shaker in the dark for further growth. Bacterial growth was observed by measuring optical density $\left(\mathrm{OD}_{600 \mathrm{~nm}}\right)$ and luminescence using a microplate reader (Synergy H1, BioTek, Canada). The data was collected every two hours, over the course of the life span of the bacteria up to $36 \mathrm{~h}$.

Varying concentrations of plant extracts were also added directly to bacteria at mid-log phase (after $24 \mathrm{~h}$ of growth) to observe their effectiveness against a culture which was at peak luminescence, indicating maximal quorum sensing.

To test the efficiency of the combinations of various extracts, holy basil, turmeric and Artemisia extracts were mixed in various combinations using $0.1 \%$ concentration of each extract. Combinations tested included holy basil and Artemisia, holy basil and turmeric, turmeric and Artemisia and holy basil, turmeric and Artemisia together. The extract combinations were added to the liquid cultures of $V$. fischeri and the observations of $\mathrm{OD}_{600 \mathrm{~nm}}$ and luminescence were recorded after $24 \mathrm{~h}$ of growth.

Assessment of anti-quorum sensing efficiency of volatile compounds (eugenol and linalool) of holy basil on bacterial growth

Two paper discs (10 $\mathrm{mm}$ in diameter) were placed on $V$. fischeri cultured Petri dishes and and soaked with varying volumes of eugenol 

compounds

and linalool $(0.1 \mu \mathrm{L}, 0.15 \mu \mathrm{L}$ and $0.2 \mu \mathrm{L})$. The plates were immediately sealed with Parafilm to avoid leakage of the volatile compounds from the Petri dish. All Petri dishes were kept in the growth conditions described above and observations for zones of inhibition were recorded after $24 \mathrm{~h}$.

For assessment using liquid medium, Erlenmeyer flasks containing $7 \mathrm{~mL}$ of LB medium were inoculated with $0.01 \%$ of $V$. fischeri. A sterile plastic pipette tip (200 $\mu \mathrm{L}$, Diamed, Ontario, Canada) with a cotton plug inserted into the tip was placed into each Erlenmeyer flask, and then sterilized by autoclaving for $20 \mathrm{~min}$ at $121^{\circ} \mathrm{C}$. Different volumes $(0,10 \mu \mathrm{L}, 50 \mu \mathrm{L} \& 100 \mu \mathrm{L})$ of eugenol and linalool (Sigma-Aldrich, Canada) were added to the cotton plug inside the plastic pipette so that the cotton plug absorbed the volatile compound within the pipette tip and there was no direct addition of the volatile compounds to the bacterial culture. Flasks were sealed immediately with Parafilm to avoid dispersion of volatile compounds into the outside atmosphere. Bacterial growth was observed by measuring $\mathrm{OD}_{600 \mathrm{~nm}}$ and luminescence at every $4 \mathrm{~h}$, for $24 \mathrm{~h}$. Three samples were collected from each of the three flasks for every treatment and the flasks were discarded after sample collection.

\section{Assessment of efficacy of volatile oils and volatile compounds on bacterial growth}

A total of seven essential oils including cinnamon (Cinnamomum verum), anise (Pimpinella anisum), cassia (Cassia fistula), clove (Eugenia caryophyllata), spearmint (Mentha spicata), lemon (Citrus limon) and lavender (Lavandula angustifolia) (LorAnn ${ }^{\text {tix }}$ oils, Lansing, MI, USA) and six liquid volatile compounds (linalool, methyl salicylate, citral, eugenol, menthol and cumin aldehyde) (Sigma-Aldrich, Canada) were selected to evaluate their inhibitory effect on bacterial growth [25]. The experiment was conducted in the manner previously described for linalool and eugenol. The control treatment was prepared without any essential oil or volatile compound. All essential oils and volatile compounds were tested for their inhibitory effect on bacterial growth using $100 \mu \mathrm{L}$ of each, and observations were recorded at 12 and $24 \mathrm{~h}$ after the treatment.

\section{Treatment of $C$. violaceum and $E$. coli with linalool and eugenol}

C. violaceum (ATCC-31523) is a strain of quorum sensing bacteria that releases a violet pigment as a result of the bacterial cell-cell communication [26,27]. The antibacterial effect of eugenol and linalool was tested against $C$. violaceum, using a Kirby Bauer disc assay and the volatile compound assay without direct contact as described above. The antibacterial effect of linalool was also tested on E. coli in the manner described previously.

\section{Effect of linalool on $V$. fischeri culture at mid-log phase}

$V$. fischeri bacterial culture was grown in liquid LB medium for 18 $\mathrm{h}$ in the control medium without any treatments. Cotton plugs soaked in linalool were placed inside of plastic pipette tips, which were then placed in the Erlenmeyer flasks containing $7 \mathrm{~mL}$ of pre-grown liquid $V$. fischeri bacterial culture.

\section{Imaging and microscopy}

Images of the bacterial plates were taken using a Cannon SLR camera under complete dark conditions. Linalool treated and untreated bacterial cultures after $22 \mathrm{~h}$ of treatment were taken for microscopy. Cells were fixed in $2 \%$ glutaraldehyde in $0.45 \mathrm{M}$ cacodylate buffer ( $\mathrm{pH}$
7.3), washed with $0.45 \mathrm{M}$ cacodylate buffer, post-fixed with $1 \%$ osmium tetroxide for $1 \mathrm{~h}$ and washed again with cacodylate buffer. The samples were subjected to dehydration with ethanol, critical point drying and sputter-coating with gold-palladium. Finally, samples were examined with a scanning electron microscope Hitachi S-570 (Hitachi High Technologies, Tokyo, Japan).

\section{Statistical analysis}

All experiments were repeated twice with three independent biological and three technical replications per treatment. All data were analyzed using JMP 10.0.0 (SAS Institute, Cary, NC) and ANOVA was conducted to determine the significance of the model followed by means comparison using Student's t test with a type II error rate of 0.05 . Data were presented as the mean plus/minus the standard error of the mean of three replications.

\section{Results}

\section{Effect of medicinal plant extracts on bacterial growth}

In Kirby Bauer disc diffusion assays, the bacterial cultures showed zones of inhibition of $20-22 \mathrm{~mm}$ around the paper discs soaked in holy basil, Artemisia and turmeric extract, with the greatest zones of inhibition present around the discs soaked in holy basil extract (Figures $1 \mathrm{~A} 1$ and 1A2). Plates were observed after $22 \mathrm{~h}$ of growth, and it was evident that with increasing amounts of holy basil extract, there were increased zones of inhibition (Data not shown).

Liquid culture assays resulted in luminescence readings which were significantly lower for bacteria treated with holy basil extract, followed by Artemisia and turmeric in comparison with the other extracts (Table 1). A $50 \%$ reduction in luminescence was observed in bacteria treated with holy basil extract as compared to the control (data not shown). As shown in Figure 1B, cultures treated with varying concentrations of holy basil had minimal OD and luminescence values, compared to the control. Similarly, cultures treated with different concentrations of Artemisia and turmeric had significantly reduced OD and luminescence values (data not shown). After $20 \mathrm{~h}$ of growth, concentrations of $1 \%$ holy basil extract or higher had significantly reduced luminescence and OD of the $V$. fischeri culture, as compared to the control. However, the lowest concentration of $0.1 \%$ was not as effective in suppressing bacterial growth and luminescence in comparison to the control. The bioluminescence of the bacterial culture containing holy basil extract at $1 \%$ concentration was lowered (67\%) after $20 \mathrm{~h}$ of growth, compared to the control. After $32 \mathrm{~h}$, there was more than $90 \%$ reduction in bioluminescence.

A mixed extract made of the lowest concentration tested $(0.1 \%)$ of holy basil, turmeric and Artemisia was an effective antibacterial agent, compared to other combinations throughout the growth period (Figures 1C1 and 1C2). Even though there was no significant difference in OD between the treatment and control, luminescence was greatly reduced when the bacteria were treated with the combination of holy basil, turmeric and Artemisia; nearly $90 \%$ reduction in luminescence after $24 \mathrm{~h}$ was observed in comparison to the control.

\section{Effect of volatile compounds of holy basil on bacterial growth}

Bacterial cultures showed zones of inhibition around the paper discs soaked in linalool and eugenol (Data not shown). Greater zones of inhibition were observed around discs soaked in the lowest concentration of linalool (Figures 2C1-2C3). Results showed that without direct contact, eugenol and linalool significantly reduced the 


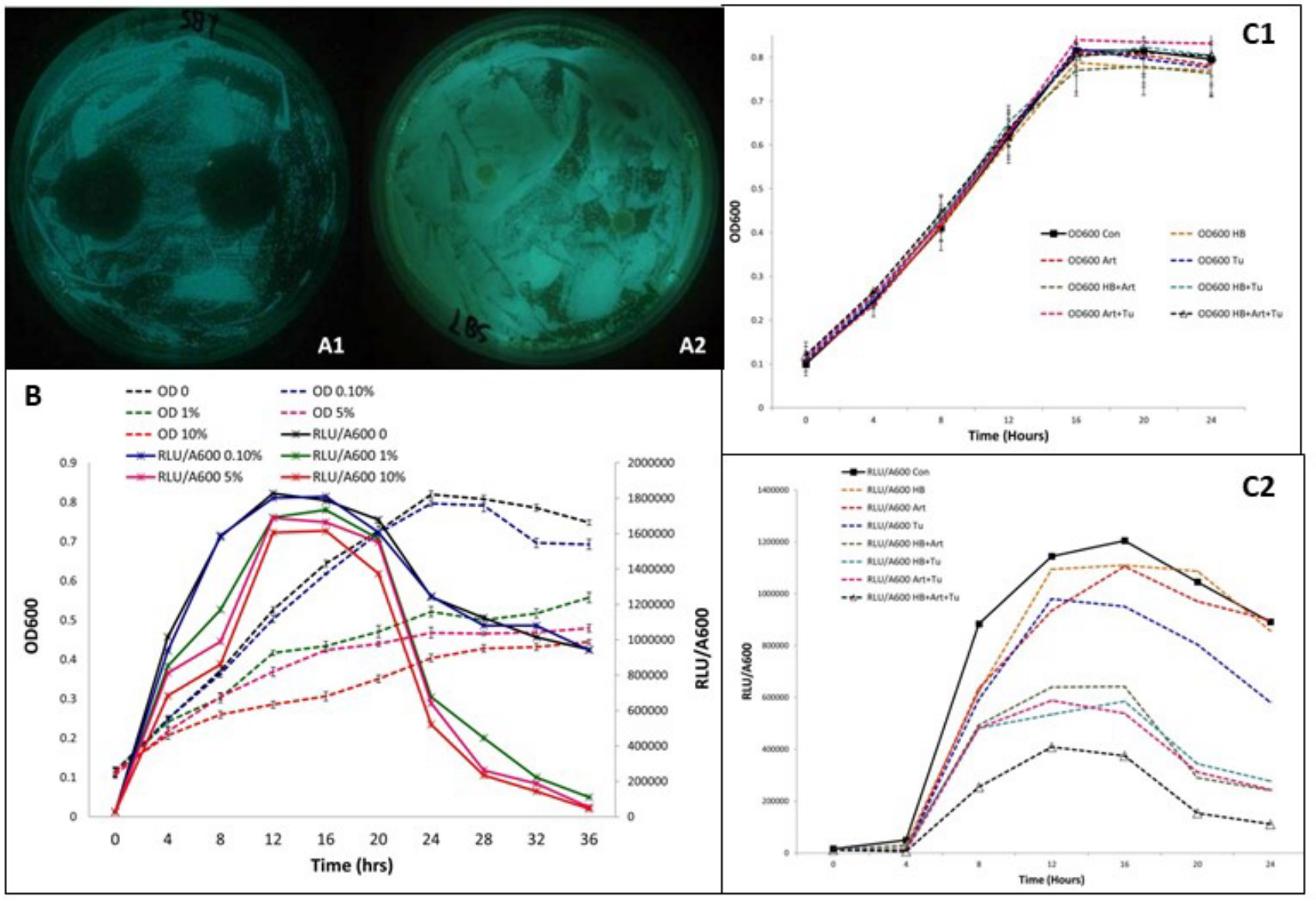

Figure 1. Zones of inhibition observed around discs soaked in $10 \%$ Holy basil aqueous extract (A1) in comparison with the control (A2) after $22 \mathrm{~h}$ of growth period. Effects of different concentrations of Holy Basil extract $(0,0.1,1.0,5.0$ and $10.0 \%)$ on $V$. fischeri growth (OD $)$ and luminescence over time (B). Effect of possible combinations of Holy Basil (HB) Artemisia (Art) and Turmeric (Tu) at their lowest concentration $(0.1 \%)$ on the growth $(\mathrm{C} 1)$ and luminescence $(\mathrm{C} 2)$ of $V$. fischeri over $24 \mathrm{~h}$. Bars represent the mean of three replications plus and minus the standard error of the mean

Table 1. Effect of various aqueous plant extracts $(5 \%)$ on the bioluminescence of $V$. fischeri and luminescence recorded after $22 \mathrm{~h}$. Data represent average values of three replicates and for means in the same column, different letters indicate significant differences among treatments using Student's t-test at $\mathrm{P}<0.05$

\begin{tabular}{|c|c|}
\hline Plant Extract & $\begin{array}{c}\text { Average } \\
\text { Luminescence (LUM) }\end{array}$ \\
\hline Nutmeg & $704883.4^{\mathrm{b}}$ \\
\hline Coriander & $699523.5^{\mathrm{b}}$ \\
\hline Cumin & $697174.9^{\mathrm{b}}$ \\
\hline Turmeric & $507168.2^{\mathrm{ab}}$ \\
\hline Artemisia & $499782.9^{\mathrm{ab}}$ \\
\hline Holy Basil & $472644.2^{\mathrm{ab}}$ \\
\hline
\end{tabular}

luminescence and growth of $V$. fischeri, at all concentrations $(10,50$, $100 \mu \mathrm{L}$ ) tested in comparison with the control (Figures $2 \mathrm{~A}$ and $2 \mathrm{~B}$ ). Linalool was a more effective antibacterial compound than eugenol, suppressing around 50\% more luminescence at $16 \mathrm{~h}$ and around $37 \%$ at peak luminescence $(24 \mathrm{~h})$. After $24 \mathrm{~h}$, the antibacterial volatile effect of linalool reduced the luminescence of the bacterial culture by $95 \%$ as opposed to the luminescence of the control. Eugenol reduced the luminescence of $V$. fischeri by $50 \%$ as compared to the control.

\section{Volatile effect of various plant volatile compounds on bacterial growth}

All the volatile compounds and volatile oils tested significantly reduced the luminescence and the concentration of $V$. fischeri through their volatile effects (without direct contact with the bacteria) throughout the growth period (Figure 3A1). Linalool, citral and lemon were among the most effective inhibitory essential oils and volatile compounds. Compared to the control, citral reduced the luminescence of $V$. fischeri by almost $85 \%$, indicating that there was very minimal quorum sensing in the presence of citral. Lemon essential oil reduced the luminescence by $80 \%$ compared to the control (Figure 3A2). In general, volatile compounds effectively inhibited luminescence and growth of the bacterial cultures.

\section{Volatile treatment of linalool and eugenol on C. violaceum}

In order to investigate if linalool and eugenol has an inhibitory effect on pathogenic bacteria, C. violaceum was used. Both compounds inhibited bacterial growth without direct contact (Figures 3B1-3B3). There was limited growth in plates streaked with the bacteria and treated with paper discs soaked in the linalool and eugenol (Figures 3B4-3B6). Average $\mathrm{OD}_{600 \mathrm{~nm}}$ for linalool (0.046) and eugenol (0.615) was significantly lower than the $\mathrm{OD}_{600 \mathrm{~nm}}$ of control $(0.815)$ after $24 \mathrm{~h}$ of treatments. Compared to the control, a much lower level of violet pigmentation was observed in the culture treated with eugenol, and no pigment was observed in the linalool treatment.

\section{Volatile effect of linalool on $E$. coli}

The volatile effect of linalool inhibited $E$. coli growth, suggesting that linalool is an efficient antibacterial agent for more than one type 
Shukla Devanshi M (2020) Quorum sensing inhibition in Vibrio fischeri: An efficient system to assess antibacterial properties of medicinal plants and their volatile compounds

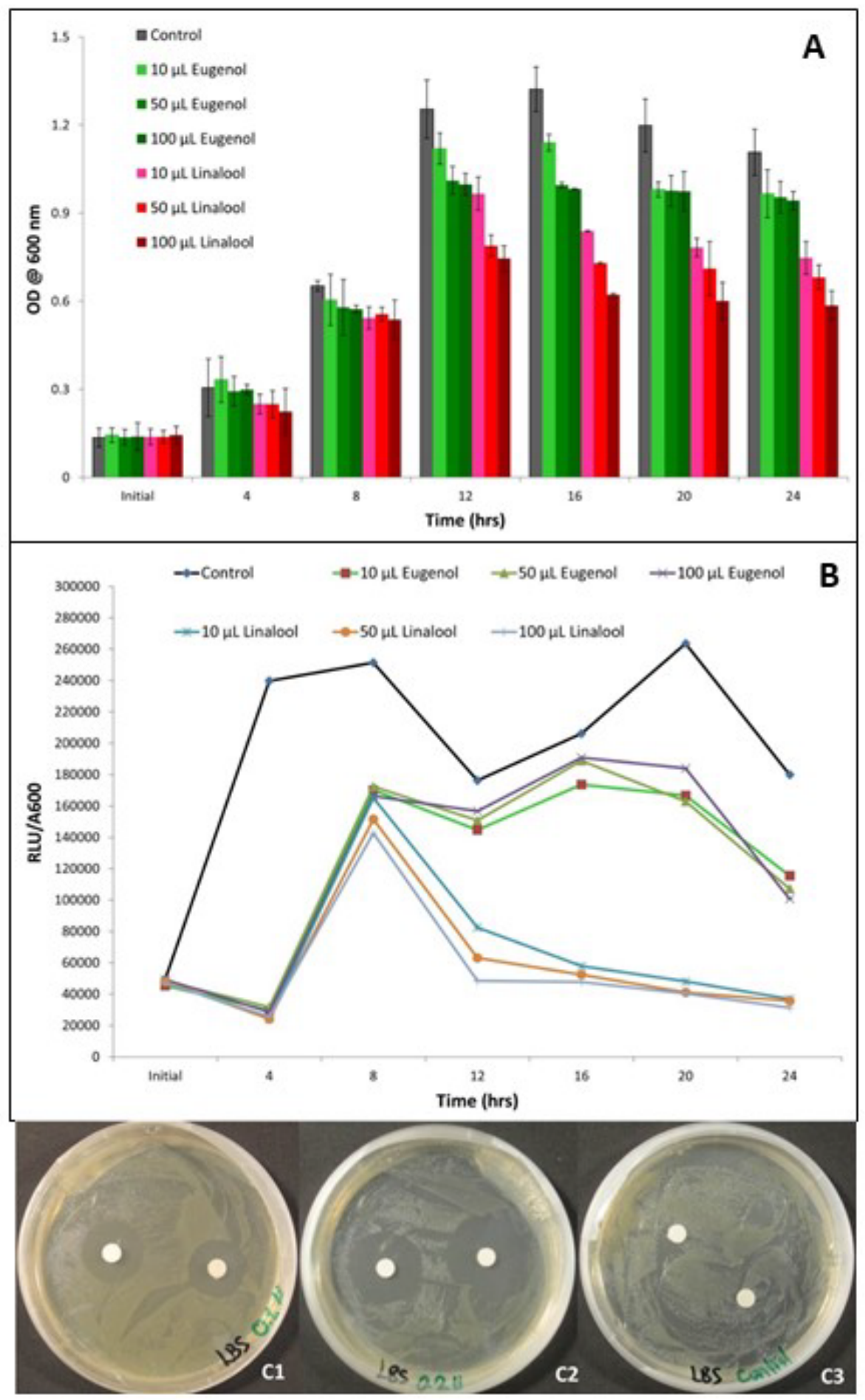

Figure 2. Effect of various concentrations $(0,10,50,100 \mu \mathrm{L})$ of volatile compounds, eugenol and linalool on optical density (A) and luminescence (B) of $V$. fischeri a $24 \mathrm{~h}$ period. Zones of inhibition observed after $22 \mathrm{~h}$ of growth around discs soaked in $0.1 \mu \mathrm{L}(\mathrm{C} 1)$ and $0.2 \mu \mathrm{L}(\mathrm{C} 2)$ of linalool in comparison with the control (C3). Bars represent the mean of three replications plus and minus the standard error of the mean 

compounds

of bacteria. After $18 \mathrm{~h}$ of treatment, the OD of E. coli bacteria treated with $100 \mu \mathrm{L}$ of linalool decreased to 0.1 compared to the control OD of 0.5 , indicating $80 \%$ reduction in growth. More than $66 \%$ reduction in E. coli growth was observed after $18 \mathrm{~h}$, with $10 \mu \mathrm{L}$ of linalool treatment, compared to control (Figure 3C). These results show that linalool has significant inhibitory effects on $E$. coli growth without contact.

\section{Volatile effect of linalool on $V$. fischeri bacteria at mid-log phase}

Linalool without contact significantly suppressed the luminescence of $V$. fischeri bacteria after being grown for $18 \mathrm{~h}$. After $4 \mathrm{~h}$ of treatment, $100 \mu \mathrm{L}$ of linalool had suppressed more than $95 \%$ of luminescence in $V$. fischeri in comparison to the control (Figure 4). It is evident that even with a large cell population, linalool still has a quorum quenching effect without direct contact.

\section{SEM microscopy}

SEM images taken of $V$. fischeri bacteria treated with $10 \mu \mathrm{L}$ of linalool after $22 \mathrm{~h}$ showed that the bacterial cells were elongated, misshapen and unable to divide compared to untreated bacteria (Figures $5 \mathrm{~A}$ and

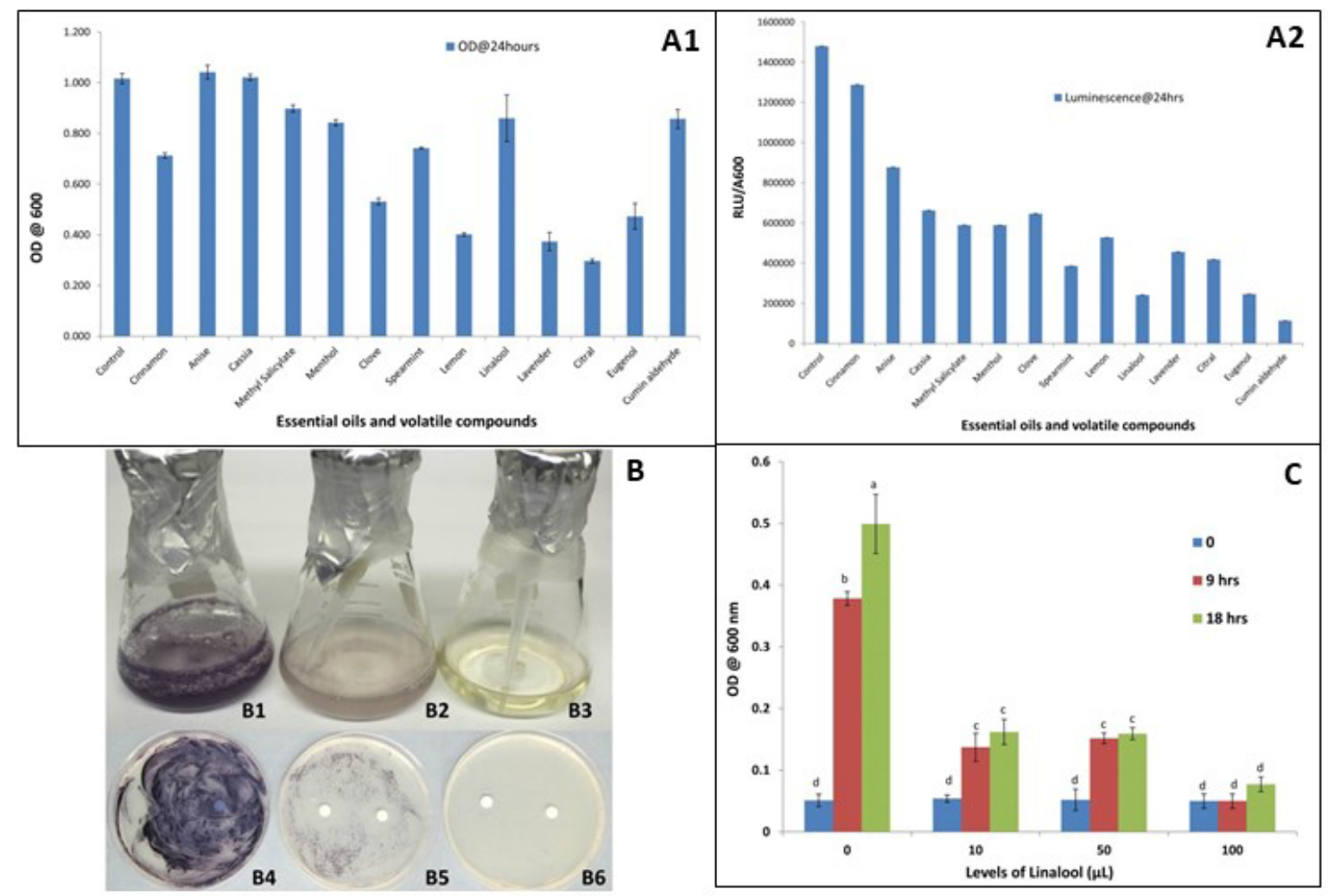

Figure 3. Inhibitory effect against bacterial optical density (A1) and luminescence (A2) of seven essential oils (Cinnamomum verum, Pimpinella anisum, Cassia fistula, Eugenia caryophyllata, Mentha spicata, Citrus limon and Lavandula angustifolia) and six volatile compounds (linalool, methyl salicylate, citral, eugenol, menthol and cumin aldehyde) using 100 $\mu \mathrm{L}$ of each after $24 \mathrm{~h}$ treatment. Volatile effect of eugenol (B2) and linalool (B3) on inhibition of quorum sensing of Chromobacterium violaceum culture as compared to control (B1) using $50 \mu \mathrm{L}$. Kirby Bauer Disc assay for Chromobacterium violaceum treated with Eugenol (B5) and Linalool (B6), volatile compounds (50 $\mu \mathrm{L})$ showing very limited growth in comparison with the control (B4) after $22 \mathrm{~h}$ of growth. Volatile effect of different levels $(0,10,50$ and $100 \mu \mathrm{L})$ of linalool on growth of $E$. coli after 9 and $18 \mathrm{~h}$ treatments $(\mathrm{C})$. Bars represent the mean of three replications plus and minus the standard error of the mean. Bars with different letters are significantly different at a $p$-value of 0.05 .

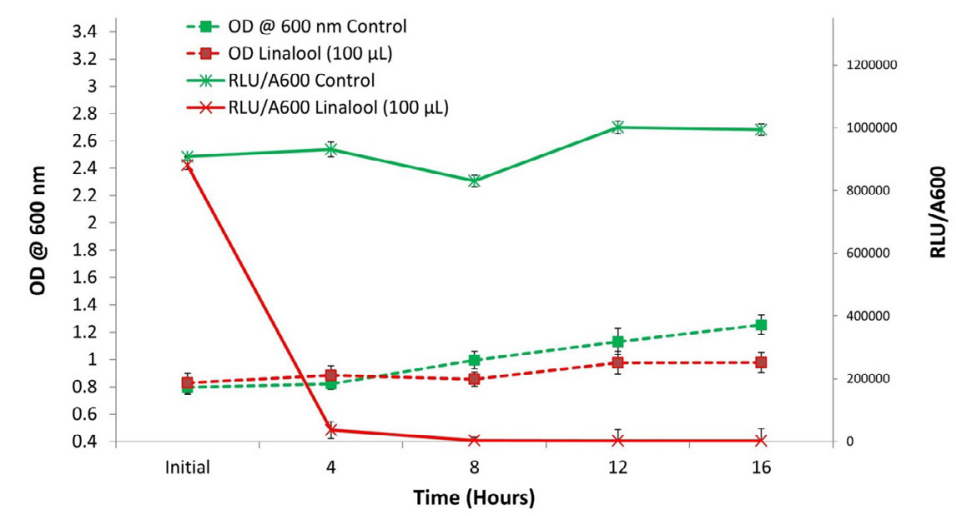

Figure 4. Volatile effect of linalool $(100 \mu \mathrm{L})$ on fully grown $V$. fischeri bacteria without contact compared to control over a $16 \mathrm{~h}$ period. Bars represent the mean of three replications plus and minus the standard error of the mean 
5B). Microscopic growth assessment showed a decreased number of bacterial cells present in the culture treated with linalool without contact, as opposed to the control culture (Figures 5C and 5D).

\section{Discussion}

Numerous studies have proven the antibacterial effect of medicinal plants $[9,10]$. The medicinal plants and their metabolites can serve as an alternate to conventional antibiotics especially with the current rise in antibiotic resistance. However, identifying and comparing antibacterial plants and their compounds with each other for their medicinal efficacy is cumbersome and time-consuming, requiring many resources $[10,14]$.

In this study, the reduction of $V$. fischeri bioluminescence and concentration in response to antibacterial plant extracts and their compounds was developed as an efficient method for screening antibacterial medicinal plants and their compounds.

Using this novel bioassay testing reduction in $V$. fischeri concentration (observed by measuring $\mathrm{OD}_{600 \mathrm{~nm}}$ ) and bioluminescence (as a result of quorum sensing inhibition), we successfully tested antibacterial properties of several plant extracts and their volatile compounds. Amongst the plant extracts tested, holy basil was the most efficient anti-quorum sensing treatment, as there was the greatest suppression of $V$. fischeri bioluminescence and reduced OD (Table 1,
Figure 1B). The reduction in the number of $V$. fischeri colonies in the plates containing Holy Basil (Figures $1 \mathrm{~A} 1$ and 1A2) confirmed the effectiveness of Holy Basil antibacterial properties on V. fischeri.

To further validate our novel $V$. fischeri bioluminescence bioassay and confirm the antibacterial properties of Holy basil, we used the standard Kirby Bauer disc diffusion assay. The results from both the bioassays ( $V$. fischeri bioluminescence bioassay and Kirby Bauer disc diffusion assays) were comparable (Figure 1); both showed the effectiveness of Holy Basil's antibacterial properties. However, the major advantage of the present bioassay over the Kirby Bauer disc diffusion assay is its ability to determine the antibacterial properties of plants without any requirement of direct contact of plant material.

Several other studies have reported holy basil as an antimicrobial agent [28-33], however the current study is the first report confirming Holy Basil's antibacterial properties by inhibition of quorum sensing of $V$. fischeri. Quorum sensing allows for group behaviours such as virulence and interfering with this mechanism would be the most optimal way to treat such an infection [23].

In general, many medicinal plants are aromatic, and the composition of their essential oils have been extensively characterized $[34,35]$. There have been multiple studies supporting the fact that volatile compounds have many uses, such as in aromatherapy or in the airborne communication and defense mechanism of plants [35-

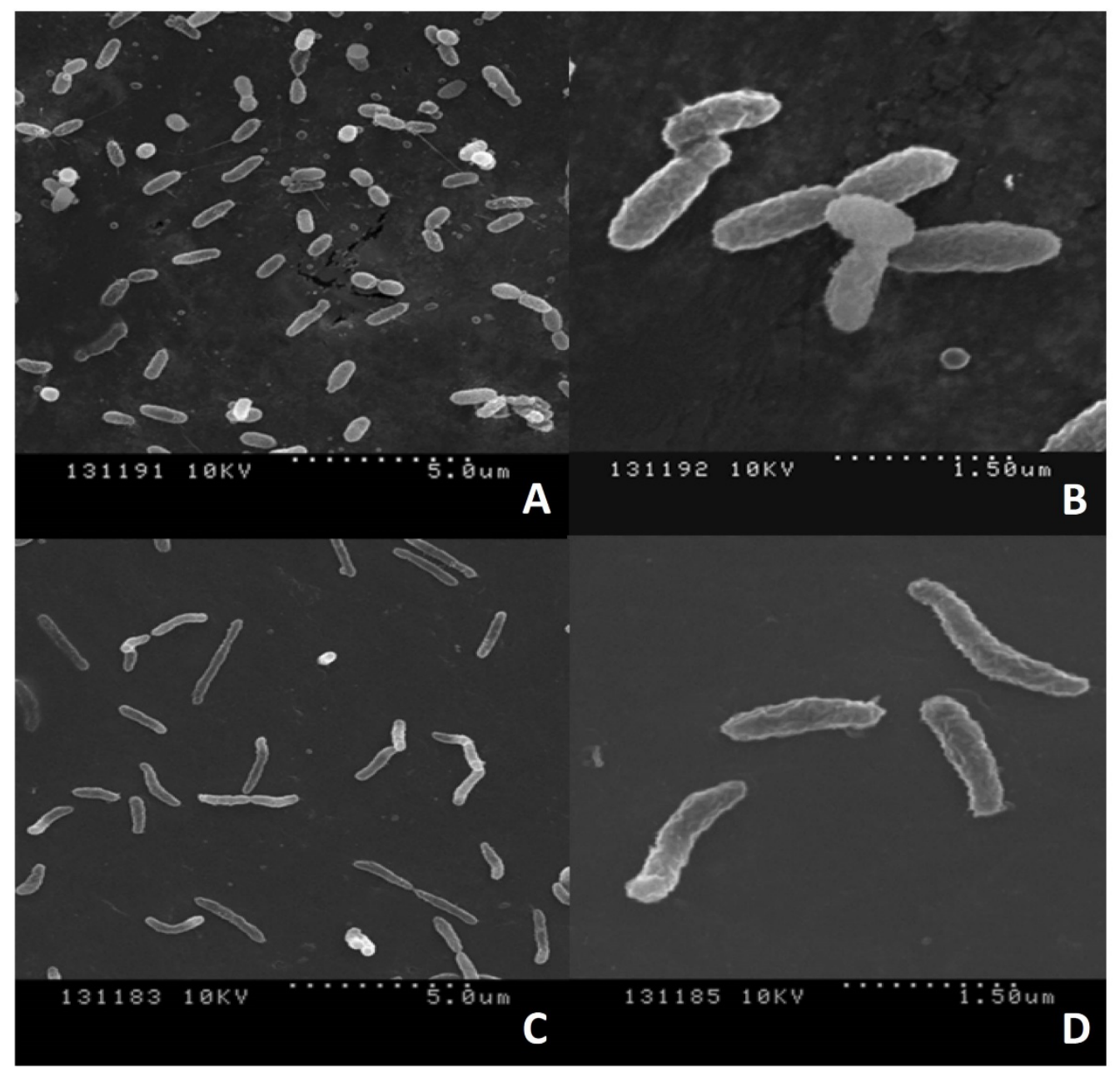

Figure 5. SEM images of $V$. fischeri - untreated (A \& B) and treated with linalool $50 \mu \mathrm{M}(\mathrm{C} \& \mathrm{D})$ without direct contact in liquid bacterial culture 

compounds

39]. However, no study on the antibacterial effect of plant volatile compounds using $V$. fischeri quorum sensing inhibition has been conducted. We tested the volatile effect of two major essential oils of holy basil namely, linalool and eugenol and found that both of these compounds were capable of interfering with quorum sensing in the bacteria without direct contact, as illustrated by the significant decrease in luminescence, even at very low concentrations (Figure 2).

Volatile organic compounds produced by specific strains of bacteria (Pseudomonas fluorescens and Serratia plymuthica) act as inhibitors of quorum sensing by decreasing the amount of autoinducers, which are responsible for mediating bacterial communication [40]. It is suggested that the volatile organic compounds and autoinducer molecules in the same strain of bacteria have a strong negative interaction, as the volatile compounds significantly suppress the transcription of genes that allow for the synthesis of autoinducers [40]. It is therefore possible that the plant volatile compounds such as eugenol and linalool also work through a similar mechanism as bacterial volatile organic compounds.

The significant antibacterial effect of plant volatiles such as citral and lemon essential oils (Figure 3 ) in addition to eugenol and linalool tested through the bioluminescence bioassay in our study further substantiate the evidence of the antibacterial properties of plant volatiles. Citral and linalool have similar structures and contain an oxygenated unsaturated alkyl chain which might be important for their antibacterial properties.

Furthermore, it is important to note that holy basil extract as well as its essential oils tested were effective in limiting bioluminescence at lower concentrations while optical density stayed relatively constant in comparison with the control. This is a novel aspect of the study as it can be deduced that at lower concentrations, the antimicrobial compounds tested have an effect on quorum sensing before optical density is limited. Inhibiting quorum sensing is of primary importance because it allows for behaviours such as virulence or antibiotic resistance and it is interesting to note that this occurs before bacterial cells are killed.

In order to confirm the antibacterial effect of the volatile compounds and validate our bioassay, we tested the volatile effect of linalool and eugenol on virulent pathogenic bacteria, C. violaceum. The inhibition of quorum sensing in Chromobacterium violaceum is observed as lack of violet pigmentation [27]. The reduction of the violet pigment in C. violaceum by linalool and eugenol (Figure 3B) confirms our bioassay and the effectiveness of these volatile compounds without contact against these pathogenic bacteria. Further the antibacterial effectiveness of eugenol and linalool was confirmed on a non-pathogenic strain of E. coli (DH5a) (Figure 3C). This experiment further substantiated the broad use of linalool and eugenol not only on bioluminescent bacteria but also on nonbioluminescent bacteria like E. coli. These results indicate the potential benefit of these plant volatiles on pathogenic $E$. coli strains. SEM imaging of $V$. fischeri treated with linalool showed that the bacterial cells were elongated, misshapen and unable to divide (Figure 5), indicating that these volatiles may interfere with bacterial cell wall structure and function. There were also a limited number of bacterial cells following the treatment, which also has an impact on the ability to conduct group behaviours.

This novel $V$. fischeri bioluminescence bioassay is an efficient and fast assay to quantify the effectiveness of antibacterial agents. Traditional methods of testing antimicrobial action are unable to determine bacterial communication [23]. This bioassay incorporates speed and ease of use, compared to estimates of zones of inhibition and bacterial cell counts. Using this innovative bioassay, numerous known and unknown antibacterial agents can be screened to determine the ones that inhibit quorum sensing, thus inhibiting the group behaviours such as virulence and not just limiting bacterial growth. This can extend to help determine the effectiveness of plant based natural health products.

The volatile compounds and essential oils used in this study effectively limited bioluminescence in $V$. fischeri, which allows for the deduction that they will be able to inhibit group behaviours like virulence and antibiotic resistance if used to treat bacterial infections. To our knowledge, this is first report of screening antibacterial volatile compounds using quorum-sensing. The bioassay developed in this study can easily screen vast number of antibacterial compounds in plants. These compounds have potential to be used against the multidrug resistant bacterial strains as alternatives to the conventional antibiotic with minimal side effects.

\section{Conclusion}

A novel bioluminescent bioassay which utilizes measuring the reduction in bioluminescence of $V$. fischeri was developed as an efficient tool to screen antibacterial plants and their compounds. This bioassay relies on the inhibition of $V$. fischeris quorum sensing and therefore its bioluminescence which can be easily detected and quantified. Using this bioassay, holy basil and its volatile compounds namely eugenol and linalool were identified as antibacterial compounds. The antibacterial effects of linalool and eugenol were confirmed by testing their effects on pathogenic bacteria, C. violaceum and E. coli through the well-accepted Kirby Bauer disc diffusion assay, further substantiating the usefulness of this bioluminescent bioassay. As such, this bioassay can be helpful in discovering novel plant based antibacterial compounds to reduce the incidence of drug-resistant bacteria and our dependence on antibiotics with harmful side-effects.

\section{Acknowledgements}

This study was funded by the Gosling Foundation, Guelph, Ontario and the Natural Sciences and Engineering Research Council of Canada. We thank Dr. Joseph Lam, University of Guelph for providing the bacterial cultures.

\section{Competing interests}

The authors declare that they have no competing interests.

\section{Author's contributions}

DS, VB, and PS were involved in the development of the hypotheses and experimental design; DS and VB conducted the majority of the experiments; DG helped troubleshoot experimental procedures, supplied bacterial strain, and participated in drafting the manuscript; DS drafted the initial manuscript, and all authors have read and approved the final manuscript.

\section{References}

1. Gallagher J (2014) Antibiotic resistance rise continues. BBC NEWS Website. http:// www.bbc.com/news/health-29553435.

2. Panasevich CL (2004) New antibiotics needed as drug resistance continues to grow. The Nation's Health, 34-37.

3. Rojas J, Ochoa V, Ocampo S, Muñoz J (2006) Screening for antimicrobial activity of ten medicinal plants used in Colombian folkloric medicine: A possible alternative in the treatment of non-nosocomial infections. BMC Complement Altern Med 6: 2. [Crossref]

4. Alviano DS, Alviano CS (2009) Plant extracts: search for new alternatives to treat microbial diseases. Current Pharmaceutical Biotechnology 10: 106-121.

5. Fankam AG, Kuiate JR, Kuete V (2015) Antibacterial and antibiotic resistance modifying activity of the extracts from allanblackia gabonensis, combretum molle and gladiolus quartinianus against Gram-negative bacteria including multi-drug resistant phenotypes. BMC Complement Altern Med 15: 206. [Crossref] 
Shukla Devanshi M (2020) Quorum sensing inhibition in Vibrio fischeri: An efficient system to assess antibacterial properties of medicinal plants and their volatile compounds

6. Kirst HA (2013) Developing new antibacterials through natural product research. Expert Opin Drug Discov 8: 479-493. [Crossref]

7. Laxminarayan R, Duse A, Wattal C, Zaidi AKM, Wertheim HFL, et al. (2013) Antibiotic resistance-the need for global solutions. Lancet Infect Dis 13: 1057-1098. [Crossref]

8. Cowan MM (1999) Plant products as antimicrobial agents. Clin Microbiol Rev 12: 564582. [Crossref]

9. Uma Devi P (2001) Radioprotective, anticarcinogenic and antioxidant properties of the Indian Holy Basil, Ocimum sanctum (Tulasi). Indian J Exp Biol 39: 185-190. [Crossref]

10. Adonizio AL, Downum K, Bennett BC, Mathee K (2006) Anti-quorum sensing activity of medicinal plants in southern Florida. J Ethnopharmacol 10: 427-435. [Crossref]

11. Wallace RJ (2007) Antimicrobial properties of plant secondary metabolites. Proc Nutr Soc 63: 621-629. [Crossref]

12. Guarrera PM, Savo V (2013) Perceived health properties of wild and cultivated food plants in local and popular traditions of Italy: A review. J Ethnopharmacol 146: 659680. [Crossref]

13. Ortega-Ramirez LA, Rodriguez-Garcia I, Leyva JM, Cruz-Valenzuela MR, SilvaEspinoza BA, et al. (2014) Potential of medicinal plants as antimicrobial and antioxidant agents in food industry: A hypothesis. J Food Sci 79: 129-137. [Crossref]

14. Whiteley M, Lee KM, Greenberg EP (1999) Identification of genes controlled by quorum sensing in Pseudomonas aeruginosa. Proc Natl Acad Sci U S A 96: 1390413909. [Crossref]

15. Spellberg B, Gilbert DN (2014) The future of antibiotics and resistance: a tribute to a career of leadership by John Bartlett. Clin Infect Dis 59: S71-S75. [Crossref]

16. Bassler BL, Losick R (2006) Bacterially Speaking. Cell 125: 237-246. [Crossref]

17. Urbanczyk H, Ast JC, Higgins MJ, Carson J, Dunlap PV (2007) Reclassification of Vibrio fischeri, Vibrio logei, Vibrio salmonicida and Vibrio wodanis as Aliivibrio. Int $J$ Syst Evol Microbiol 57: 2823-2829. [Crossref]

18. Eberhard A, Burlingame AL, Eberhard C, Kenyon GL, Nealson KH, et al. (1981) Structural identification of autoinducer of Photobacterium fischeri luciferase. Biochemistry 20: 2444-2449.

19. Stevens AM, Greenberg EP (1997) Quorum sensing in Vibrio fischeri: Essential elements for activation of the luminescence genes. J Bacteriol 179: 557-562. [Crossref]

20. Waters CM, Bassler BL (2005) Quorum sensing: cell-to-cell communication in bacteria. Ann Rev Cell Dev Biol 21: 319-346. [Crossref]

21. Deep A, Chaudhary U, Gupta V (2011) Quorum sensing and bacterial pathogenicity: From molecules to disease. J Lab Physicians 3: 4-11. [Crossref]

22. Hastings J, Greenberg EP (1999) Quorum sensing: The explanation of a curious phenomenon reveals a common characteristic of bacteria. Journal of Bacteriol 181: 2667-2668. [Crossref]

23. Miller MB, Bassler BL (2001) Quorum sensing in bacteria. Annu Rev Microbiol 55: 165-199. [Crossref]

24. Boynton L (2009) Using bioluminescent bacteria to detect water contaminants. Environment 4: 1-14.
25. Prabuseenivasan S, Jayakumar M, Ignacimuthu S (2006) In vitro antibacterial activity of some plant essential oils. BMC Complement Altern Med 6: 39. [Crossref]

26. McClean KH, Winson MK, Fish L, Taylor A, Chhabra SR, et al. (1997) Quorum sensing and Chromobacterium violaceum: Exploitation of violacein production and inhibition for the detection of N-acylhomoserine lactones. Microbiology 143: 37033711. [Crossref]

27. Zhu H, He CC, Chu QH (2011) Inhibition of quorum sensing in Chromobacterium violaceum by pigments extracted from Auricularia auricular. Lett Appl Microbiol 52: 269-274. [Crossref]

28. Kumar A, Shukla R, Singh P, Dubey N (2010) Chemical composition, antifungal and antiaflatoxigenic activities of Ocimum sanctum L. essential oil and its safety assessment as plant based antimicrobial. Food Chem Toxicol 48: 539-543. [Crossref]

29. Joshi B, Sah G, Basnet B, Bhatt M, Sharma D, et al. (2011) Phytochemical extraction and antimicrobial properties of different medicinal plants: Ocimum sanctum (Tulsi), Eugenia caryophyllata (Clove), Achyranthes bidentata (Datiwan) and Azadirachta indica (Neem). J Microbiology and Antimicrobial 3: 1-7.

30. Ali H, Dixit S (2012) In vitro antimicrobial activity of flavanoids of Ocimum sanctum with synergistic effect of their combined form. Asian Pacific Journal of Tropical Disease 2: S396-S398.

31. Kalia VC (2013) Quorum sensing inhibitors: An overview. Biotechnol Adv 31: 224 245. [Crossref]

32. Choudhury SS, Bashyam L, Manthapuram N, Bitla P, Kollipara P, et al. (2014) Ocimum sanctum leaf extracts attenuate human monocytic (THP-1) cell activation. $J$ Ethnopharmacol 154: 148-155. [Crossref]

33. Rastogi S, Meena S, Bhattacharya A, Ghosh S, Shukla R, et al. (2014) De novo sequencing and comparative analysis of holy and sweet basil transcriptomes. $B M C$ Genomics 15: 588. [Crossref]

34. Zheljazkov V, Cantrell C, Tekwani B, Khan S (2008) Content, composition, and bioactivity of the essential oils of three basil genotypes as a function of harvesting. $J$ Agric Food Chem 56: 380-385. [Crossref]

35. Vani S, Cheng S, Chuah C (2009) Comparative study of volatile compounds from genus Ocimum. Journal of Applied Sciences 6: 523-528.

36. Lis-Balchin M (1997) Essential oils and "aromatherapy": their modern role in healing. $J$ R Soc Health 117: 324-329. [Crossref]

37. Heil M, Silva Bueno JC (2007) Within-plant signaling by volatiles leads to induction and priming of an indirect plant defense in nature. Proc Natl Acad Sci U S A 104: 54675472. [Crossref]

38. Karban R (2008) Plant behaviour and communication. Ecology Letters 11: 727-739.

39. Efferth T, Greten HJ (2012) Medicinal and aromatic plant research in the 21 st century Medicinal \& Aromatic Plants 1: e110.

40. Chernin L, Toklikishvili N, Ovadis M, Kim S, Ben-Ari J, et al. (2011) Quorum-sensing quenching by rhizobacterial volatiles. Environ Microbiol Rep 3: 698-704. [Crossref]

Copyright: (C2020 Shukla Devanshi M. This is an open-access article distributed under the terms of the Creative Commons Attribution License, which permits unrestricted use, distribution, and reproduction in any medium, provided the original author and source are credited. 